\title{
ON THE OPTIMAL STRUT-AND-TIE MODELS AND DESIGN APPROACH FOR THE CABLE-PYLON ANCHORAGE ZONE
}

\author{
Nannan CUI ${ }^{1}$, Shiping HUANG ${ }^{2}$ \\ ${ }^{1}$ School of Transportation Engineering, Shandong Jianzhu University, Jinan, P.R. China \\ ${ }^{2}$ School of Civil Engineering and Transportation, South China University of Technology, Guangzhou, P.R. China
}

Received 08 September 2018; accepted 20 March 2019

\begin{abstract}
The cable-pylon anchorage zone is a typical D-region in a cable-stayed bridge, for which there has been no uniform simplified design method until now. In this paper, based on the extensive statistics of actual projects, topology optimization techniques and principle of minimum strain energy, two precise strut-and-tie models for the cable-pylon anchorage zone are proposed, which can clearly reveal the load-transmitting mechanism of the anchorage zone. The explicit geometric parameters of the strut-and-tie models are derived; thus, the designers can directly use these models. A simple design procedure to deploy prestressing tendons in the anchorage zone is also introduced, whose effectiveness and convenience are demonstrated by two design examples. A new design named the "one-way prestressing tendons PC cable-pylon" is also discussed regarding its application scope.
\end{abstract}

Keywords: cable-pylon anchorage zone, strut-and-tie model, topology optimization, prestressing tendon, design approach.

\section{Introduction}

The PC cable-pylon anchorage zone in a cable-stayed bridge is a typical stress-disturbed region (D-region) that accounts for its geometrical discontinuities, which makes it a vital part and difficult to design. However, the existing standards and codes do not offer special guidelines for the pylon anchorage zone, so its design often relies on a trial-and-error process, which includes complicated FEM analysis (Wu, Lu, \& Chen, 2017; Xia, A. Li, J. Li, \& Duan, 2017) and expensive full-scale model experiments (Ye, Li, Xu, Xiao, \& Qiang, 2014). This process is inefficient, uncertain, and largely dependent on the experience of the designers. Therefore, it is necessary to recognize the mechanical behavior of the cable-pylon anchorage zone and simplify the design.

Researchers have attempted to find an optimal design approach of the pylon anchorage zone. The plane frame model was used to study the horizontal ultimate strength (Ji, 2005; Zhai, 2008). However, the slenderness ratio of the pylon wall can hardly satisfy the assumption of the beam element, which may introduce relatively big errors. The strut-and-tie model (STM) is an effective method to cope with the D-region (He \& Liu, 2010; Schlaich, Kurt, \& Mattias, 1987) and has been recommended by several codes (CSA, 1994; ACI Committee 318, 2008; Association of State Highway and Transportation Officials [AASHTO], 2004, 1999; Eurocode 2, 2004; CEB-FIP MC 90, 1993). Several researchers have introduced the STM to the pylon anchorage zone design (Zhu, Wang, \& Feng, 2017; Meng, Wu, \& Zheng, 2016; Xiong, Liu, Tian, \& Song, 2013), but they focused on one specific project without devising a universal conclusion. Thus, designers must establish and solve the strut-and-tie models by themselves, which demands higher technical requirements for them. Tao (2012), Tao, Ye, $\mathrm{Hu}$, and $\mathrm{Xu}$ (2017a, 2017b) proposed a formula based on the STM to quantitatively design prestressing tendons in cable-pylons, but the precise model has not been provided. In addition, without sufficient theoretical foundation, the formula cannot provide an overall reflection of the mechanical characteristics. Furthermore, the formula cannot determine the position of the prestressing tendons.

In this paper, the stress distribution patterns of the anchorage zone are divided into two categories depending on the width of the pylon wall. Two optimal strut-andtie models are proposed based on topology optimization (Bendsoe \& Sigmund, 2013; Jia, Misra, Poorsolhjouy, \& Liu, 2017), and the explicit geometric parameters are

\footnotetext{
${ }^{*}$ Corresponding author. E-mail: ctasihuang@scut.edu.cn
} 


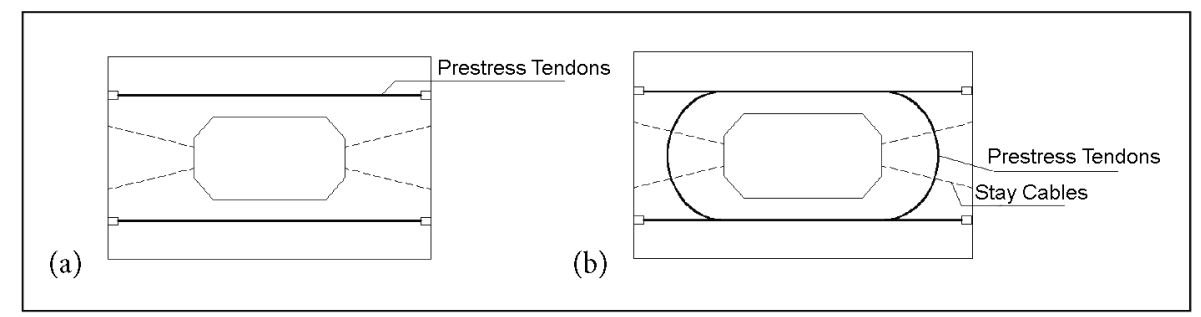

Figure 1. Layout of the prestressing tendons: (a) one-way tendons; (b) U tendons

derived based on the principle of minimum strain energy so that designers can directly use the strut-and-tie models. Finally, a simple design process to determine the quantity and positions of prestressing tendons in the anchorage zone is introduced, and two examples are provided to illustrate its effectiveness. The proposed models and design process are built on rational bases. They reveal the loadtransmitting mechanism of the anchorage zone and considerably facilitate the design.

Another purpose of the research in this paper is to study the application scope of a new design, "one-way prestressing tendons PC cable-pylon" (Cui, Jia, Yu, Yang, \& Yan, 2015; Cui et al., 2016), which is shown in Figure 1(a). Unlike the traditional "U tendons" (Figure 1(b)), the prestressing tendons are only arranged on a longitudinal direction wall in the "one-way tendons PC cable-pylon", and the shear force in the transverse direction wall, which is produced by the cable force, is resisted by only the thick concrete wall. The new design makes the cable-pylon more feasible in construction and prestress loss estimation. It has been applied in 3 long-span cable-stayed bridges in Guangdong Province, China (Cui et al., 2016), but the indepth research remains insufficient.

\section{Initial configuration of the STM}

\subsection{Simplification of the load and boundary condition}

Taking the standard height of the segmental cable-pylon as the research object, the simplified horizontal plane model is shown in Figure 2. The tapered haunches at the corners of the concrete wall are neglected. The horizontal component of the cable force in the bearing capacity limit

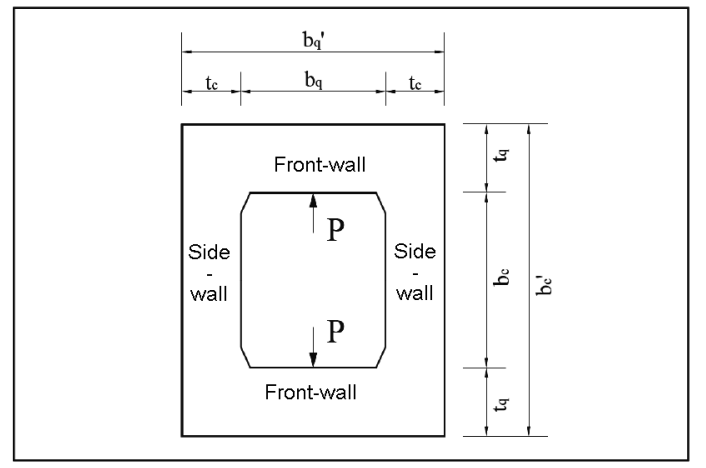

Figure 2. Horizontal plane model of the segmental cable-pylon state is simplified as a concentrated load $\mathrm{P}$ at the midpoint of the inner surface of the front-wall. The cable-pylons with two cables anchored in one front-wall are similarly treated because the distance between two cables is usually relatively small (Tao, 2007; Tao \& Xiao, 2008). In Figure 2, $t_{q}$ and $b_{q}$ are the thickness and width of the front-wall, respectively.

\subsection{Statistics of the section dimension of cable-pylon}

Instead of only considering the safety and rationality of the anchorage zone, the dimensions of the PC cablepylon are mainly determined by the global response of the bridge (Su, Yang, Qin, \& Wu, 2012). Therefore, for the general applicability of the proposed strut-and-tie model, it is necessary to investigate the range of dimensions of PC cable-pylons in actual projects. Because the dimensions of the side-wall hardly affect the strut-and-tie model of the anchorage zone (Tao, 2007), this paper focuses on the front-wall and defines $\lambda=t_{q} / b_{q}$ as the ratio between the thickness and the width of the front-wall. In total, 64 actual cable-stayed bridges in China have been investigated regarding the dimensions of the cable-pylon, and the distribution of $\lambda$ is shown in Figure 3. In the 64 samples, the minimum value of $\lambda$ is 0.345 , and the maximum is 0.833 . The value of $\lambda$ in $(0.4,0.5)$ accounts for the largest proportion of $37.5 \%$, but $\lambda$ is generally evenly distributed between 0.35 and 0.85 . Thus, the cable-pylons with $\lambda$ of $[0.3,0.9]$ are worthy of study.

To establish the strut-and-tie model, the stress trajectory method and load path method can be used for simple structures (Schlaich et al., 1987). For complex structures, it was always intractable until Liang, Xie, and Steven (2000),

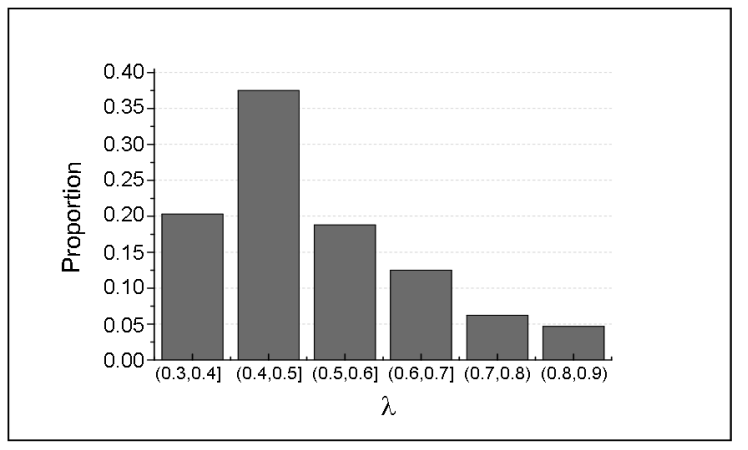

Figure 3. Distribution of $\lambda$ topology optimization of the horizontal plane model of cable-pylon 


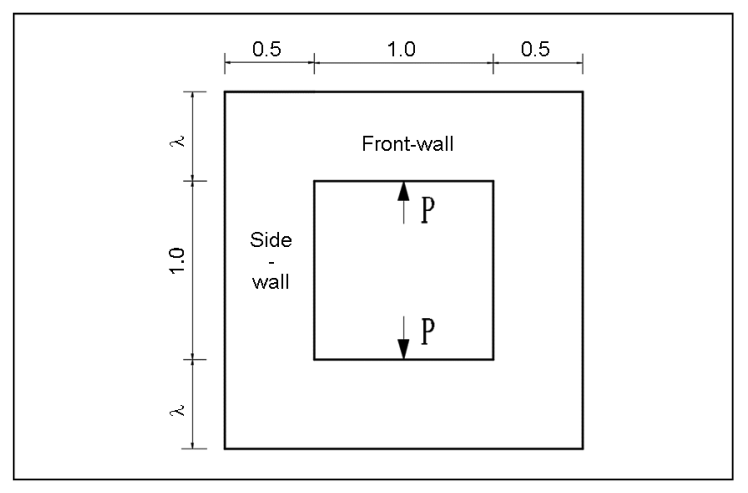

Figure 4. Initial design domain of the anchorage zone

Liang and Steven (2002) and Liang, Brian, and Steven (2002) proposed that the strut-and-tie model could be established through topology optimization.

The proposed evolutionary structural optimization (ESO) by Xie and Steven (1993) is used in this paper to find the initial configuration of the strut-and-tie model for the anchorage zone. The ESO uses the "hard-kill" approach, which introduces finite-element changes into the optimization process based on certain criteria. The criteria can be von Mises stress or other sensitivities such as the stiffness, weight, and frequency. For the maximum stiff- ness topology design, the criterion is commonly a smooth strain energy density, i.e., by gradually "killing" the elements with lower smooth strain energy densities from the initial design domain, the optimal structure will be obtained. The performance index $(P I)$ is used to measure the efficiency of the topology, which was proposed by Liang and Steven (2002) and Liang et al. (2002) as:

$$
P I=\frac{C_{0} V_{0}}{C_{i} V_{i}},
$$

where $C_{0}$ and $V_{0}$ are the mean compliance and actual volume of the initial design domain, respectively; $C_{i}$ and $V_{i}$ are the mean compliance of the structure and actual volume in the $i$ th iteration, respectively. The topology optimization objective is to maximize the PI.

The initial design domains of the anchorage zone, which will change with the value of $\lambda$, is shown in Figure 4 . Neglecting the effect of the side-wall size, the width is set as 1 , and the thickness is 0.5 . The four-node squareplane element with the length of $1 / 40$ is used. Two parameters related to the ESO are $R R$ (rejection rate) $=0.01 ; E R$ (evolution rate $)=0.01$. The optimal topology is obtained when the maximum PI occurs, and the results with different $\lambda$ values are shown in Figure 5.

The optimal topology in Figure 5 represents the main load transfer mechanism and can be considered the ini-

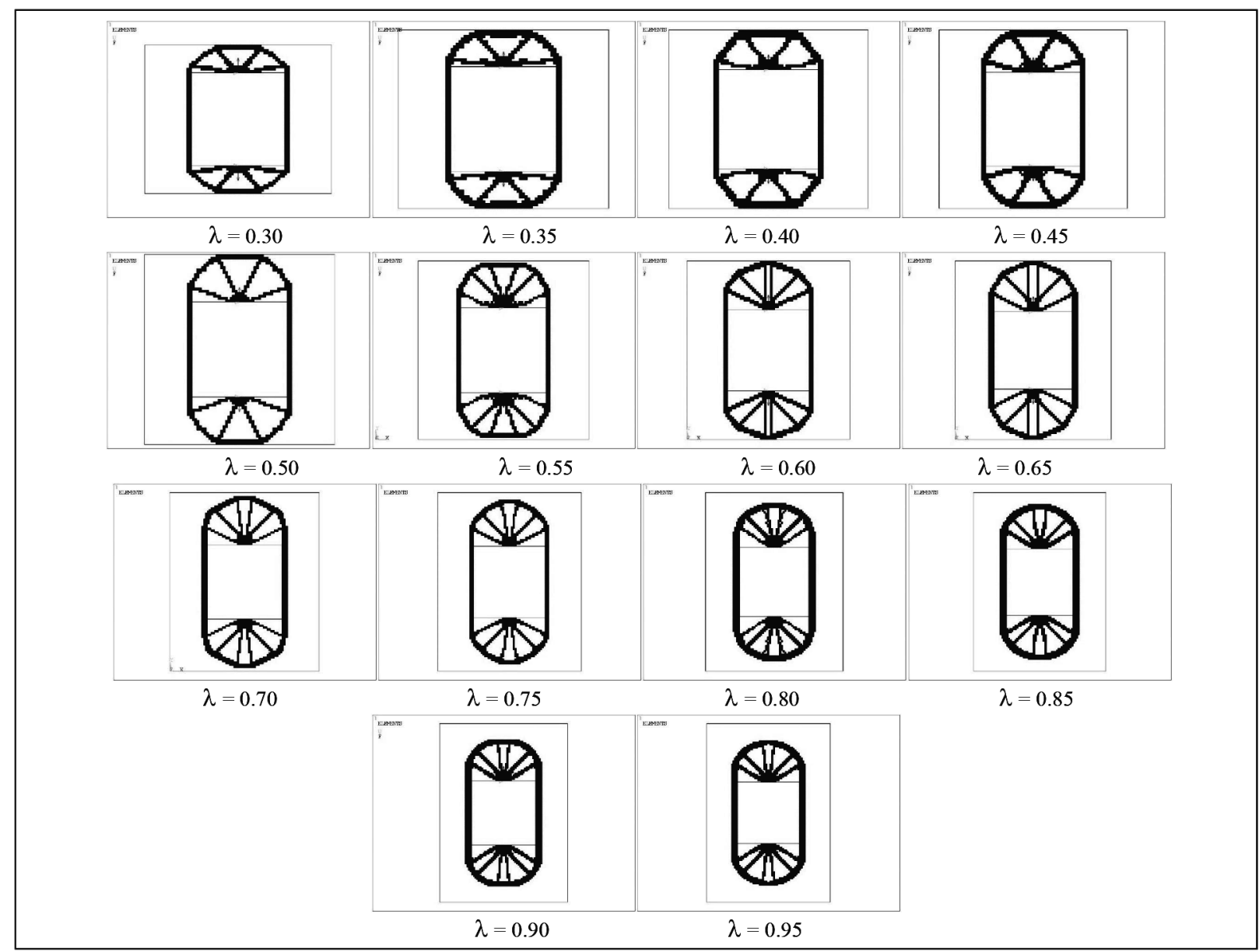

Figure 5. Optimal topology of the cable-pylon anchorage zone 
tial configuration of the strut-and-tie model. In the initial configuration, two categories are observed: when $\lambda<0.6$, there is no vertical bar generated on the symmetric line of the front-wall; when $\lambda \geq 0.6$, one vertical bar (or two bars with a small angle between each other) is generated. After $\lambda$ reaches a certain value, the height of the arch formed by the bars in the front-wall will no longer change, and the apex of the arch will separate from the outer edge of the front-wall. When $\lambda$ is small and limited by the thickness of the front-wall, the arch cannot be fully developed, and the top of the arch degenerates to a horizontal bar.

Then, we can classify the anchorage zone into two categories according to the presence of a vertical bar on the symmetric line of the front-wall: thin anchorage zone $(\lambda<$ $0.6)$ and thick anchorage zone $(\lambda \geq 0.6)$.

\section{Precise STM of the anchorage zone}

\subsection{Thin anchorage zone $(\lambda<0.6)$}

According to the optimal topology of cable-pylon anchorage zone, the load transfer mechanism of thin anchorage zone can be idealized as the STM in Figure 6, where only half of the structure is shown because of the symmetry. The side-wall is abstracted into a tie $T_{3}$ parallel to load $P$. In the front-wall, load $P$ is first transferred to the archlike ties $\left(T_{1}, T_{2}\right)$ through the radial struts $\left(C_{1}, C_{2}\right)$ and subsequently transferred to $T_{3}$ in the side-wall. This STM consists of three types of ties and two types of struts with different lengths and forces; thus, this model is named “3T2S" for brevity.

We vectorized the optimal topology of the thin anchorage zone using the professional software WinTopo Pro and measured the geometric parameters of the initial configuration of the STM. Then, we found that the angle $\alpha_{1}$ is approximately $45^{\circ}$, whereas the other geometric parameters are uncertain. However, because the STM is a lower-bound plasticity solution, any possible STM model that satisfies the force equilibrium and does not violate the yield criteria can be developed, but only the STMs with lower strain energy should be accepted considering the limited ductility of concrete (Tjhin \& Kuchma, 2007). Thus, this paper has derived explicit geometric parameters of the STM based

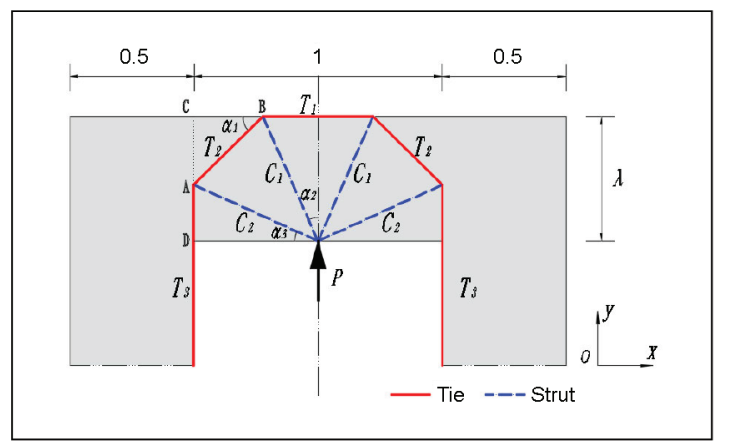

Figure 6. STM of the thin anchorage zone (1/2) on the minimum strain energy principle (He \& Liu, 2010; Schlaich et al., 1987), which can be expressed as:

$$
U=\frac{1}{2} \sum F_{i} l_{i} \varepsilon_{i} \Rightarrow \min ,
$$

where $F_{i}, l_{i}$ and $\varepsilon_{i}$ are the force, length and mean strain of the ith bar in the STM, respectively.

Because the concrete struts have a much larger stiffness than the reinforcing steel ties, most of the strain energy in the entire STM is caused by the ties. Because the reinforcement number of ties is calculated based on the yield strength of reinforcement, Eqn (2) can be transformed into:

$$
U_{T}=\frac{1}{2} \sum F_{T_{i}} l_{T_{i}} \varepsilon_{y} \Rightarrow \min ,
$$

where $F_{T_{i}}$ and $l_{T_{i}}$ are the force and length of the $i$ th tie, respectively; $\varepsilon_{y}$ is the yield strain of reinforcement. Eqn (3) implies that the strain energy of a tie can be measured with only its length and force.

According to the geometric relationship in Figure 6, a series of equations can be obtained:

$$
\begin{aligned}
& l_{T_{1}}=2 \lambda \tan \alpha_{2} \\
& l_{A C}=l_{B C}=\frac{1}{2}-\frac{l_{T_{1}}}{2}=\frac{1}{2}-\lambda \tan \alpha_{2} \\
& l_{A D}=\lambda-l_{A C}=\lambda-\frac{1}{2}+\lambda \tan \alpha_{2} \\
& l_{T_{2}}=\csc \alpha_{1} \cdot l_{A C}=\frac{\sqrt{2}}{2}-\sqrt{2} \lambda \tan \alpha_{2} \\
& l_{C_{2}}=\sqrt{l_{A D}{ }^{2}+\left(\frac{1}{2}\right)^{2}}=\sqrt{\left(\lambda-\frac{1}{2}+\lambda \tan \alpha_{2}\right)^{2}+\left(\frac{1}{2}\right)^{2}} \\
& \tan \alpha_{3}=2 l_{A D}=2 \lambda-1+2 \lambda \tan \alpha_{2} \\
& l_{T_{3}}=b_{c}+l_{A D}=\frac{b_{c}}{2}+\lambda-\frac{1}{2}+\lambda \tan \alpha_{2}
\end{aligned}
$$

where $b_{c}$ is the width of the side-wall, which is a known variable.

According to the equilibrium of force in the $y$ direction:

$$
F_{T_{3}}=\frac{P}{2}
$$

For the isolated 1/4 part of the structure based on symmetry, according to the moment equilibrium in the loading location:

$$
F_{T_{1}}=\frac{P}{4 \lambda} .
$$

For the isolated point $\mathrm{A}$, according to $\sum F_{X}=0$ :

$$
F_{C_{2}} \cdot \cos \alpha_{3}-F_{T_{2}} \cdot \cos \alpha_{1}=0 \text {. }
$$




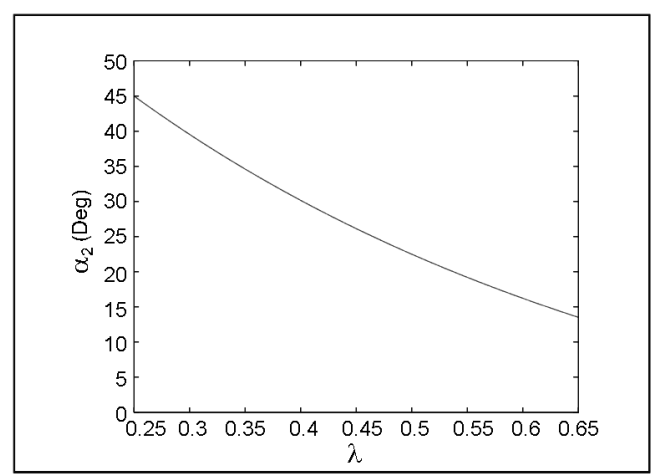

Figure 7. $\alpha_{2}-\lambda$ curve of the STM for the thin anchorage zone

According to $\sum F_{Y}=0$ :

$F_{T_{3}}=F_{C_{2}} \cdot \sin \alpha_{3}+F_{T_{2}} \cdot \sin \alpha_{1}$.

Consociating Eqns (13), (14), (8) and (10), we obtain:

$$
F_{T_{2}}=\frac{P}{2 \sqrt{2} \lambda\left(1+\tan \alpha_{2}\right)} .
$$

Obviously, the length and force of all ties in Figure 6 can be expressed by $\alpha_{2}$ and $\lambda$, which implies that for a certain STM of the thin anchorage zone, only the angle of $\alpha_{2}$ is unknown. The strain energy of ties is:

$$
\begin{aligned}
& U_{T}=\frac{1}{2} \varepsilon_{y} \sum F_{T_{i}} l_{T_{i}}= \\
& \frac{1}{2} \varepsilon_{y} P\left[\frac{1-2 \lambda \tan \alpha_{2}}{\lambda\left(1+\tan \alpha_{2}\right)}+\tan \alpha_{2}+b_{c}+2 \lambda-1+2 \lambda \tan \alpha_{2}\right] .
\end{aligned}
$$

To minimize the strain energy of ties, the angle of $\alpha_{2}$ should satisfy:

$$
\frac{\partial U_{T}}{\partial \alpha_{2}}=0 \text {. }
$$

Solving Eqn (17), we obtain:

$$
\frac{-\sec ^{2} \alpha_{2} \cdot(2 \lambda+1)}{\lambda\left(1+\tan \alpha_{2}\right)^{2}}+\sec ^{2} \alpha_{2}+2 \lambda \sec ^{2} \alpha_{2}=0 \text {. }
$$

Therefore, the angle of $\alpha_{2}$ can be obtained from Eqn (18), and the relationship between $\alpha_{2}$ and $\lambda$ is shown in Figure 7, which reveals that the angle of $\alpha_{2}$ decreases with increasing $\lambda$. This conclusion is consistent with the optimal topology of the anchorage zone in Figure 5.

Because the formulation of $\alpha_{2}-\lambda$ is complex and for convenient engineering application, the binomial fitting method is used for Eqn (18), and a simple expression of $\alpha_{2}$ is obtained:

$$
\alpha_{2}=1.3602 \lambda^{2}-2.5827 \lambda+1.3429 .
$$

The fitted curve of $\alpha_{2}-\lambda$ is shown in Figure 8 .

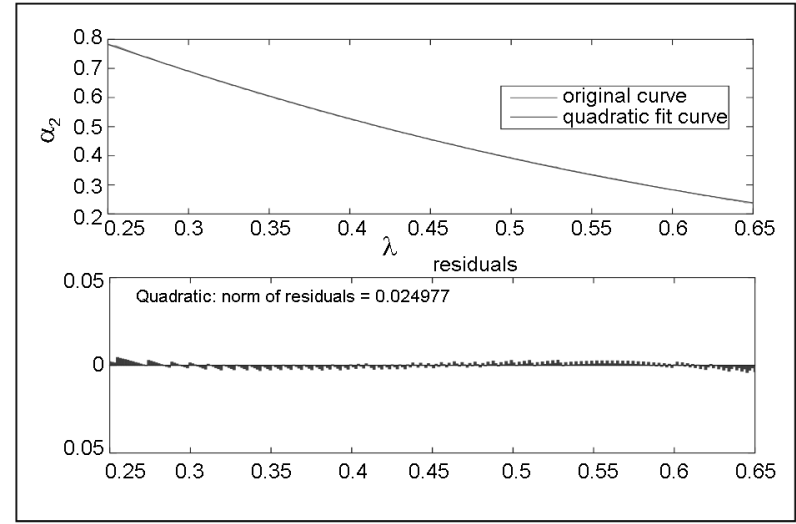

Figure 8. $\alpha_{2}-\lambda$ fitted curve of the STM for the thin anchorage zone

\subsection{Thick anchorage zone $(\lambda \geq 0.6)$}

The strut-and-tie model of the thick anchorage based on the optimal topology can be established as shown in Figure 9. In the front-wall, load $P$ is first transferred to the arch-like ties $\left(T_{1}, T_{2}\right)$ through the radial struts $\left(C_{1}, C_{2}\right.$, $C_{3}$ ) and subsequently transferred to $T_{3}$ in the side-wall. Compared with the thin anchorage zone, the arch consisting of ties $\left(T_{1}, T_{2}\right)$ of the thick anchorage zone is fully developed into a semicircle, which benefits from the sufficiently large $\lambda$ and results in the appearance of strut $C_{1}$. This STM consists of three types of ties and struts with different lengths and forces, so it is named the "3T3S" model.

By vectorizing the optimal topology of the thick anchorage zone in Figure 5, we find that the STM is a model of certainty, which implies that the main geometric parameters will not change with $\lambda$; except when $0.6 \leq \lambda<0.65$, the model is uniformly scaled. By measuring the vectorgraphs of the optimal topology, we obtain the main geometric parameters of the $3 \mathrm{~T} 3 \mathrm{~S}$ model as $l_{C_{1}}=l_{C_{2}}, \alpha_{1}=41^{\circ}$, and $\alpha_{2}=26^{\circ}$; when $0.6 \leq \lambda<0.65, h=\lambda$; when $\lambda \geq 0.65$, $h=0.65$.

\subsection{Internal force analysis for the STM}

By setting the horizontal component of cable force $P$ as 1 , according to Eqns (19), (11), (12) and (14), we can calcu-

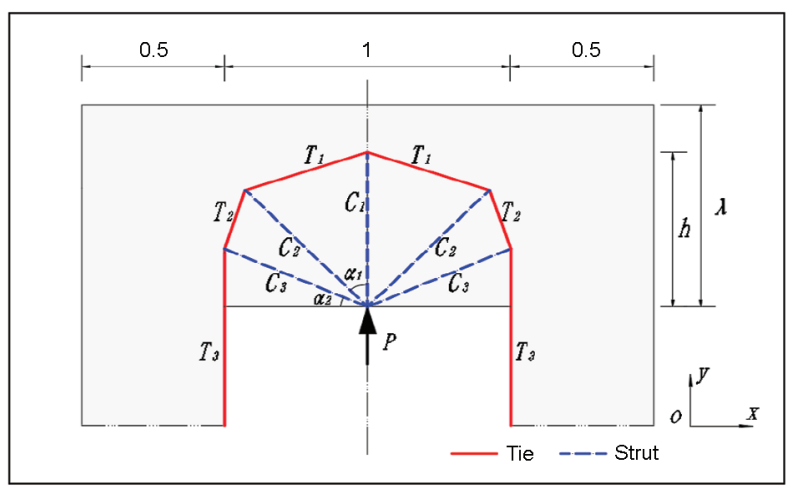

Figure 9. STM of the thick anchorage zone (1/2) 
late the force of the ties in the 3T2S model as shown in Table 1 . In Table 1 , when $\lambda<0.5$, the tie with the largest force locates in the front-wall, and the force increases with decreasing $\lambda$. When $\lambda=0.5$, the force of all ties is one half of $P$. When $\lambda>0.5$, the force of the ties in the front-wall is smaller than $0.5 P$. In general, the front-wall takes more tension than the side-wall when $\lambda$ is relatively small.

For the 3T3S model, which is deterministic, the force of the ties can be calculated as: $F_{T_{1}}=0.41 P, F_{T_{2}}=0.45 P$, and $F_{T_{3}}=0.50 \mathrm{P}$. As indicated, the $3 \mathrm{~T} 2 \mathrm{~S}$ model has larger forces of the ties in the front-wall than the 3T3S model, which implies that the front-wall is more dangerous in the thin anchorage zone.

In order to verify the proposed models, the solution of tensile force of $T_{1}$ is compared to the stress integration by FEM. As shown in Figure 10, the models proposed in this paper have good accuracy. The maximum difference is $7.7 \%$, which occurs at $\lambda=0.35$. In most cases, the calculated stresses by proposed model are higher than FEM results, which ensure a safer design.

Table 1. Force of the bars in the 3T2S model

\begin{tabular}{|c|c|c|c|c|}
\hline$\lambda$ & $P$ & $F_{T_{1}}$ & $F_{T_{2}}$ & $F_{T_{3}}$ \\
\hline 0.3 & 1 & 0.83 & 0.65 & 0.50 \\
\hline 0.35 & 1 & 0.71 & 0.60 & 0.50 \\
\hline 0.4 & 1 & 0.63 & 0.56 & 0.50 \\
\hline 0.45 & 1 & 0.56 & 0.53 & 0.50 \\
\hline 0.5 & 1 & 0.50 & 0.50 & 0.50 \\
\hline 0.55 & 1 & 0.45 & 0.48 & 0.50 \\
\hline
\end{tabular}

\section{Design of prestressing tendons based on the STM}

\subsection{Design procedure}

The $3 \mathrm{~T} 2 \mathrm{~S}$ or $3 \mathrm{~T} 3 \mathrm{~S}$ model should first be established according to the value of $\lambda$. On the premise of ensuring the minimum thickness of the concrete cover, the prestressing tendons should be arranged along the trace of ties. More specifically, in the thin anchorage zone, the prestressing tendons should be near the outer edge of the front-wall and inner edge of the side-wall, whereas in the thick anchorage zone, they should be arranged like a semicircle whose radius is 0.65 times of the width of the front-wall (or approximately the thickness when $0.6 \leq \lambda<0.65$ ).

Supposing that all tension of the ties is resisted by the prestressing tendons, according to the ACI $318-08$ provisions, the required area of the prestressing tendon $A_{p}$ can be calculated as:

$$
A_{p} \geq \frac{T_{s}}{\phi \sigma_{p e}},
$$

where $\phi=0.75$ is the strength reduction factor, and $\sigma_{p e}$ is the effective prestress considering the prestress loss. When the prestressing tendons are curved, $\sigma_{p e}=0.6 \sigma_{c o n}$, where $\sigma_{c o n}$ is the controlled prestress in construction. When the prestressing tendons are straight, $\sigma_{p e}=0.74 \sigma_{\text {con }}$ (Cui et al., 2016).

It is noted that the Eqn (20) considers the service limit state. If it is for the ultimate limit state, then the yield strength of prestressing steel $f_{p f}$ would be used instead of $\sigma_{p e}$.

\subsection{Design examples}

To demonstrate the effectiveness of the design procedure based on the proposed STM, two design examples for thin and thick anchorage zones according to actual projects are provided in this section. To study the one-way prestressing tendons PC cable-pylon, both $\mathrm{U}$ tendons and one-way tendons are applied in each example.

\subsubsection{Thin anchorage zone}

In this example, the dimensions of the thin anchorage zone are shown in Figure 11, which is drawn based on Wukouhe Bridge (Tang, 2006). The cable force is $7737 \mathrm{kN}$, and its horizontal component is $6700 \mathrm{kN}$. $\lambda=0.414$; $\alpha_{2}=29^{\circ}$; according to Eqn (19), a similar STM to Figure 6 can be established. If the $\mathrm{U}$ tendons are applied, the prestressing tendons should be arranged along the trace of the ties, as shown in Figure 11 (left half structure), and the

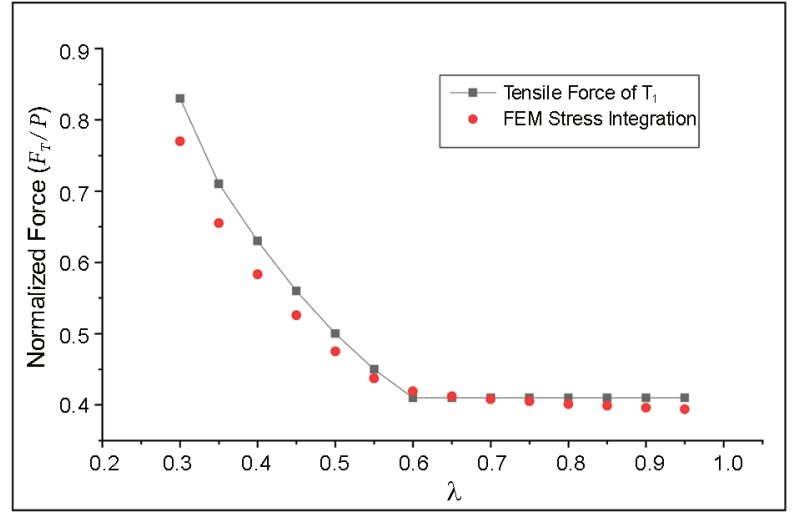

Figure 10. Numerical verification of the proposed STMs

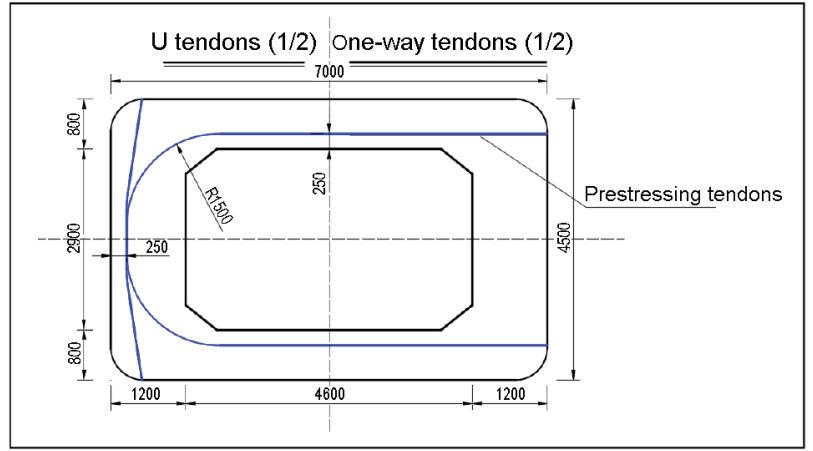

Figure 11. Dimension of the design example (thin anchorage zone) (Unit: $\mathrm{mm}$ ) 
thickness of the concrete cover is $250 \mathrm{~mm}$. If the one-way tendons are applied, the tendons are arranged as shown in Figure 11 (right half structure).

The properties of one prestressing steel strand to be used are as follows: the nominal diameter is $15.24 \mathrm{~mm}$; the nominal area is $140 \mathrm{~mm}^{2}$; the elasticity modulus is $1.95 \times 10^{5} \mathrm{MPa}$; the standard value of ultimate strength is $1860 \mathrm{MPa}$; the controlled prestress in construction is $\sigma_{\text {con }}=1395 \mathrm{MPa}$.

According to Eqns (11), (12) and (14), the force of three ties is as follows: $F_{T_{1}}=4046 \mathrm{kN} ; F_{T_{2}}=3679 \mathrm{kN}$; $F_{T_{3}}=3350 \mathrm{kN}$. In fact, the force of three ties is resisted by the same prestressing tendons, so in Eqn (20), $T_{S}=\max \left\{F_{T_{1}}, F_{T_{2}}, F_{T_{3}}\right\}$, and the required minimum area of prestressing tendons in the $\mathrm{U}$ tendons can be calculated as:

$$
A_{p} \geq \frac{T_{s}}{\phi \sigma_{p e}}=\frac{4046 \times 1000}{0.75 \times 0.6 \times 1395}=6445.2 \mathrm{~mm}^{2} \text {. }
$$

The number of prestressing steel strands is 6445.2 / 140 $=46$. In practice, $16 \varphi 15.24$ prestressing tendons arranged in three rows are provided in one segmental cable-pylon of standard height, and the total number of prestressing steel strands is $16 \times 3=48$.
To compare two forms of prestressing tendon arrangement, supposing that the total amount of steel is identical with the $\mathrm{U}$ tendons, the amount of steel strands in the oneway tendons is 87 .

The linear elastic FEM analysis using the software ANSYS is applied to verify the effect of the design. The concrete entities are simulated by the elastic element SOILD45. The prestressing tendons are simulated by element LINK8. With prestress loss, the prestress force is applied by the initial strain. The cable sleeve is simulated by element SHELL63. The effect of the reinforcement is ignored. The vertical displacement (direction Y) of nodes at the bottom is constrained. The displacement in the longitudinal direction of the bridge (direction $\mathrm{Z}$ ) and transverse direction of the bridge (direction $\mathrm{X}$ ) are constrained at the symmetry axis of the bottom surface.

The analysis results of two forms are shown in Table 2 and Figure 17. In Figure 17, the origin of horizontal coordinate $\mathrm{X}$ is located at the symmetric center of the frontwall's outer surface. The stress nephograms of cable-pylon are shown in Figure 12 and Figure 13.

As indicated, the cable-pylon arranged with $U$ tendons according to the proposed design procedure in this paper

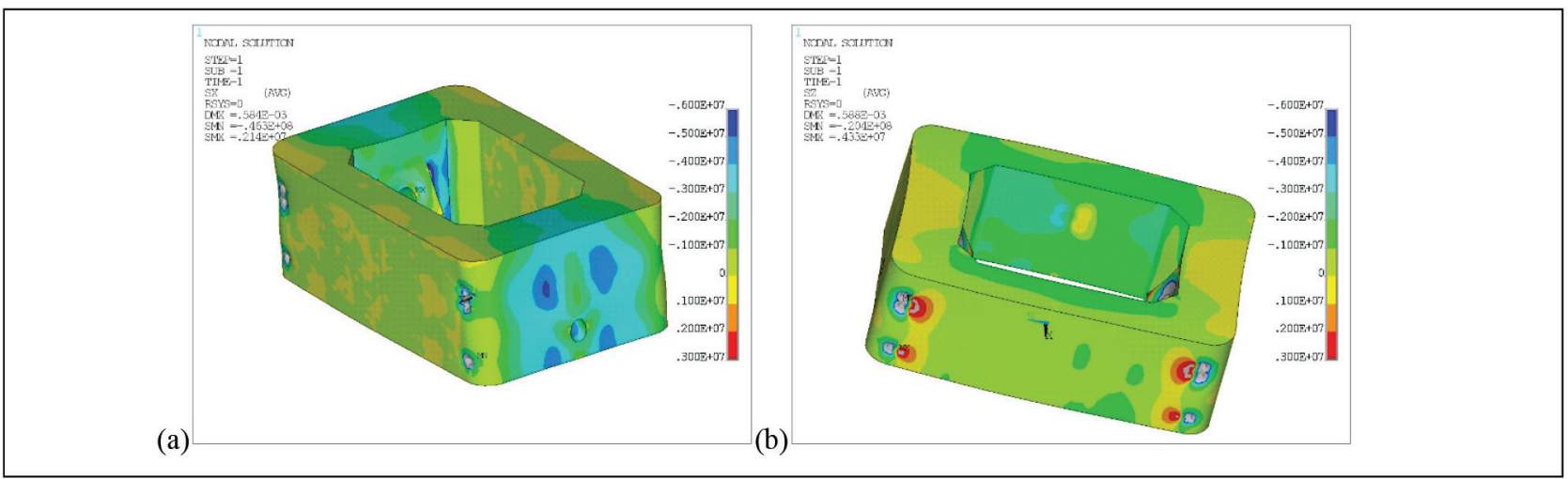

Figure 12. Stress nephograms of the cable-pylon with $\mathrm{U}$ tendons $(\mathrm{Pa})$ : (a) stress in the transverse direction of the bridge (direction $\mathrm{X}$ ); (b) stress in the longitudinal direction of the bridge (direction $\mathrm{Z}$ )

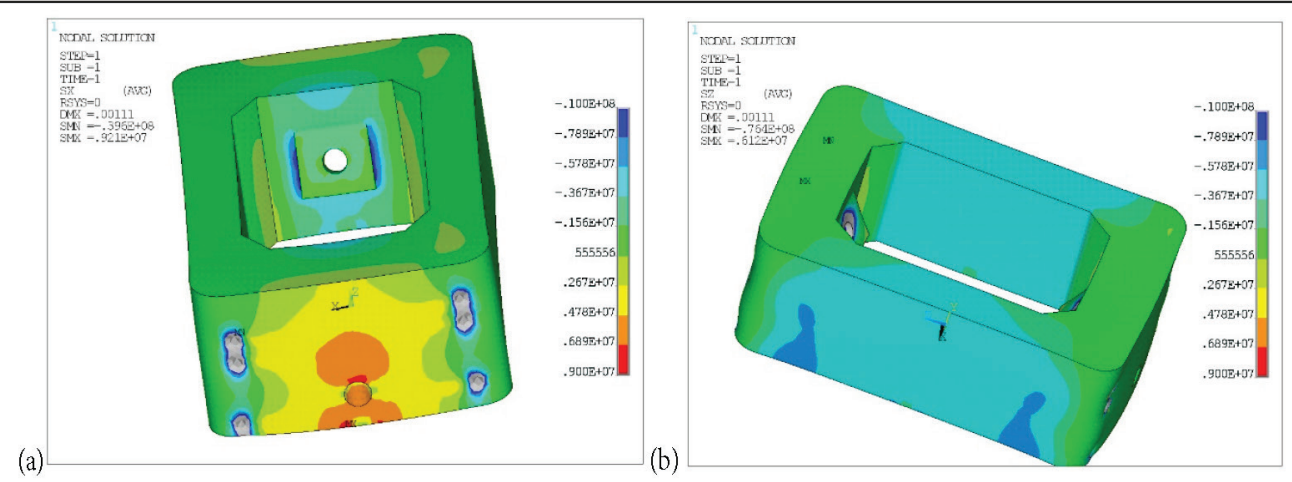

Figure 13. Stress nephograms of cable-pylon with one-way tendons (Pa): (a) stress in the transverse direction of the bridge (direction $\mathrm{X}$ ); (b) stress in the longitudinal direction of the bridge (direction $\mathrm{Z}$ ) 


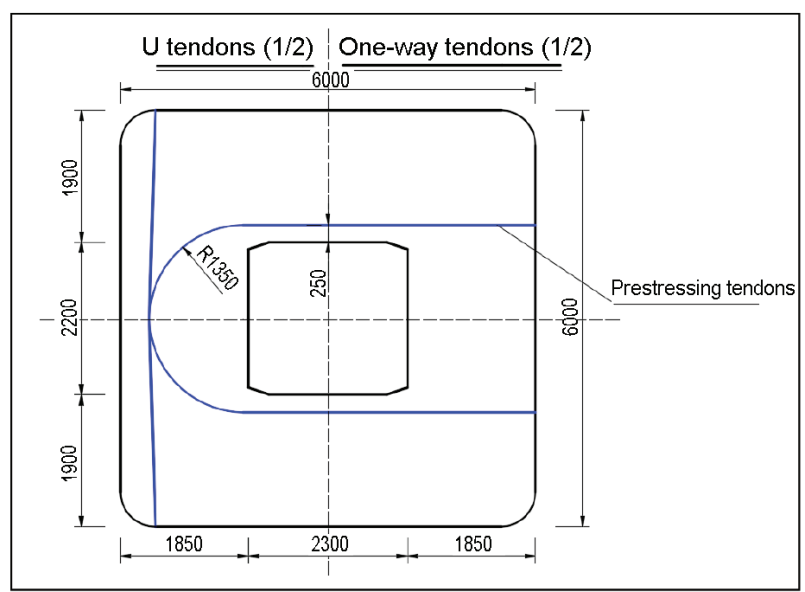

Figure 14. Dimension of the design example (thick anchorage zone) (Unit: $\mathrm{mm}$ )

performs notably well. Under the designed cable force, the tensile stress has not been observed in the front-wall and the most area of the side-wall, except for the anchorage area of the prestressing tendons. However, for the cablepylon arranged with one-way tendons, although sufficient compressive stress is reserved in the side-wall, almost the entire front-wall suffers from the high level tensile stress of approximately 2.67 6.89 MPa, which is notably dangerous and disallowed in actual structures.

In this design example, the tie with the largest force in the STM locates in the front-wall, but there are no prestressing tendons in the front-wall of the one-way tendon cablepylon, which is unreasonable. As illustrated in Table 1, the tie in the front-wall has the largest tension in the entire thin anchorage zone, except when $\lambda=0.55$; hence, the new design of one-way tendons may not be suitable for the thin anchorage zone.

\subsubsection{Thick anchorage zone}

In this example, the dimensions of the thick anchorage zone are shown in Figure 14, which is drawn based on Xijiang waterway Bridge. The cable force is $7737 \mathrm{kN}$ with a horizontal component of $6700 \mathrm{kN}$. With $\lambda=0.826$, a similar STM to Figure 9 can be established. If the $U$ tendons are applied, the prestressing tendons should be arranged along the trace of ties, as shown in Figure 14 (left half structure). If one-way tendons are applied, the tendons are arranged as shown in Figure 14 (right half structure).

The properties of one prestressing steel strand are identical to those described in Section 3.2.1. According to Section $2.3, F_{T_{1}}=2747 \mathrm{kN} ; F_{T_{2}}=3015 \mathrm{kN} ; F_{T_{1}}=3350 \mathrm{kN}$; $T_{S}=\max \left\{F_{T_{1}}, F_{T_{2}}, F_{T_{3}}\right\}$, then:

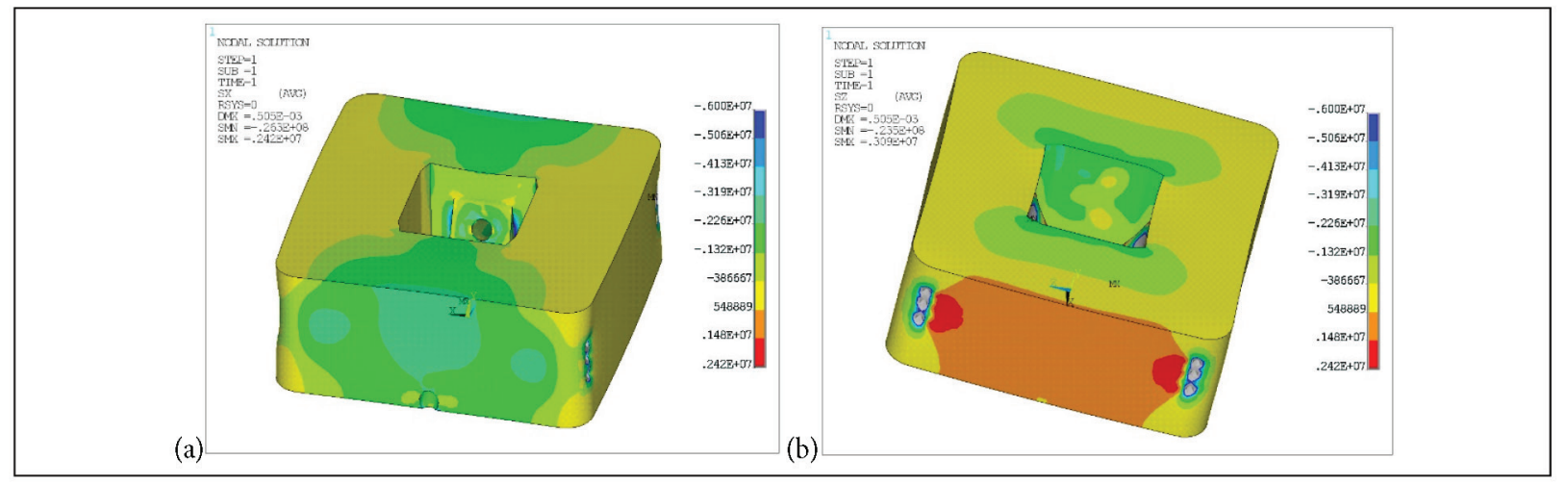

Figure 15. Stress nephograms of cable-pylon with $\mathrm{U}$ tendons $(\mathrm{Pa})$ : (a) stress in the transverse direction of the bridge (direction $\mathrm{X}$ ); (b) stress in the longitudinal direction of the bridge (direction $\mathrm{Z}$ )

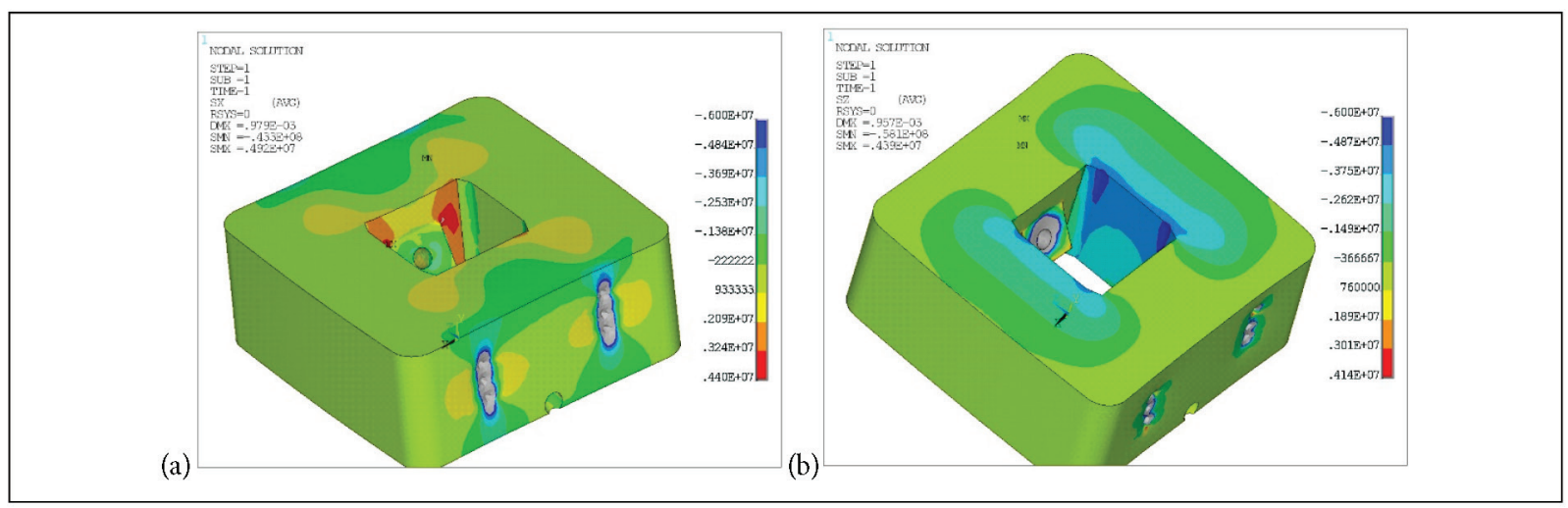

Figure 16. Stress nephograms of the cable-pylon with one-way tendons $(\mathrm{Pa})$ : (a) stress in the transverse direction of the bridge (direction $\mathrm{X}$ ); (b) stress in the longitudinal direction of the bridge (direction $\mathrm{Z}$ ) 
Table 2. Stress and deformation of representative parts of anchorage zone

\begin{tabular}{|l|c|c|c|c|}
\hline \multirow{2}{*}{} & \multicolumn{2}{|c|}{ Thin anchorage zone $(\lambda=0.414)$} & \multicolumn{2}{c|}{ Thick anchorage zone $(\lambda=0.826)$} \\
\cline { 2 - 5 } & $\mathrm{U}$ tendons & One-way tendons & $\mathrm{U}$ tendons & One-way tendons \\
\hline $\begin{array}{l}\text { Maximum horizontal tensile stress on the outer } \\
\text { surface of front-wall }\end{array}$ & 0 & 6.89 & 0 & 0.35 \\
\hline $\begin{array}{l}\text { Maximum horizontal compressive stress on the } \\
\text { inner surface of side-wall }\end{array}$ & -3.16 & -7.21 & -2.76 & -6.22 \\
\hline Maximum deformation of front-wall $(\mathrm{mm})$ & 0.2 & 0.36 & 0.13 & 0.3 \\
\hline
\end{tabular}

Note: ${ }^{\star \star}$ Anchorage areas of the prestressing tendons are not counted.

$$
A_{p} \geq \frac{T_{s}}{\phi \sigma_{p e}}=\frac{3350 \times 1000}{0.75 \times 0.6 \times 1395}=5336.5 \mathrm{~mm}^{2} .
$$

The number of prestressing steel strands is 6445.2 / 140 $=46$. In practice, $13 \varphi 15.24$ prestressing tendons arranged in three rows are provided in one segmental cable-pylon of standard height, and the total number of prestressing steel strands is $13 \times 3=39$.

To compare two forms of prestressing tendon arrangement, supposing that the total amount of steel is identical with $U$ tendons, the number of steel strands in one-way tendons is 84 .

The analysis results of two forms are shown in Table 2 and Figure 17. The stress nephograms of cable-pylon are shown in Figure 15 and Figure 16.

For the cable-pylon arranged with $U$ tendons, under the designed cable force, the tensile stress does not appear in the front-wall. In the superficial zone of the side-wall, the tensile stress of $1 \mathrm{MPa}$ arises from the bending action, which is easily overcome with reinforcement. In general, the cable-pylon arranged with $U$ tendons according to the proposed design procedure performs well.

In the cable-pylon arranged with one-way tendons, the sufficient compressive stress of approximately 1.50 4.87 MPa is reserved in the side-wall. A small tensile stress less than $0.35 \mathrm{MPa}$ distributes on the outside surface of the front-wall, which does not threaten the safety of the structure. Some tensile stress arises on the inside surface of the front-wall, but it will be settled by reinforcement.

In this design example, both U-tendons and one-way tendons can satisfy the engineering requirement, but the stress condition of the entire cable-pylon with one-way tendons is not as desirable as that with $U$ tendons. However, the advantage of one-way tendons is the convenience and economy in construction, and the sufficiently reserved compressive stress in the side-wall (Cui et al., 2015). According to Section 2.3, the tie with the largest force in the STM of the thick anchorage zone locates in the side-wall, and the tie near the outer surface of the front-wall only has the tension of $0.41 P$. Thus, compared with the thin anchorage zone, the one-way tendons, for which there are no prestressing tendons in the front-wall, are more suitable for the thick anchorage zone.

\section{Conclusions}

In this paper, two precise strut-and-tie models for cablepylon anchorage zones are proposed, and a design procedure to deploy prestressing tendons in anchorage zones is developed. The proposed STMs are based on the extensive statistics of actual projects, topology optimization technique and principle of minimum strain energy, which

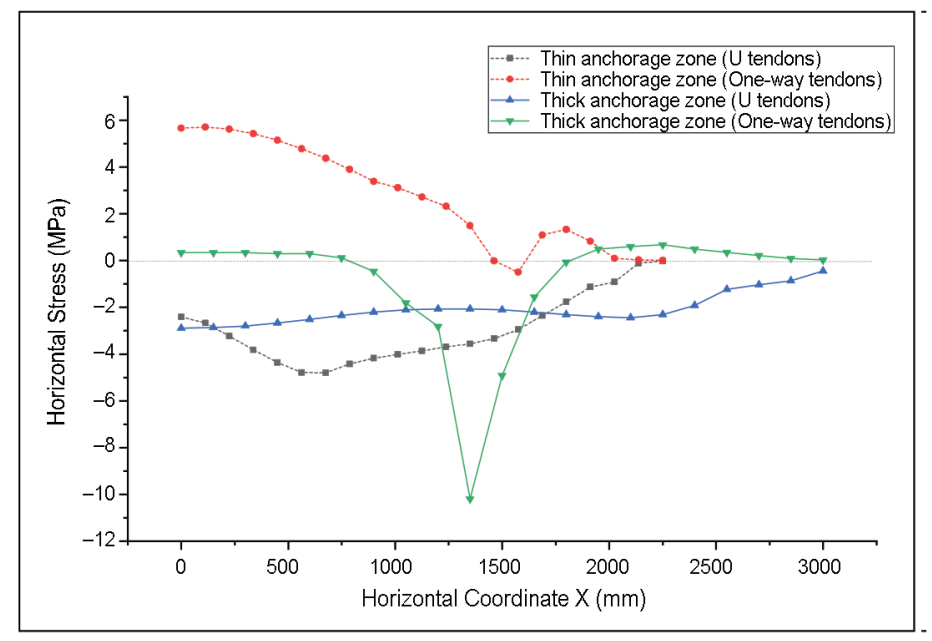

Figure 17. Distribution of horizontal stress of front-wall along the horizontal direction 
makes these models rational and effective. The major findings of this study are summarized as follows:

1. The cable-pylon anchorage zone can be divided into two categories: thin and thick anchorage zones, which should be treated differently in the design.

2 . For the thin anchorage zone $(\lambda<0.6)$, the load transfer mechanisms can be idealized as the 3T2S model, whose geometric parameters change with $\lambda$. For the thick anchorage zone $(\lambda \geq 0.6)$, the 3T3S model can be established, whose geometric parameters are $\lambda$-independent.

3. According to ACI 318-08 (ACI Committee 318, 2008), a design procedure for deploying prestressing tendons in anchorage zones based on the 3T2S and 3T3S models is developed, which can avoid the blindness and low effectiveness in the traditional design. Two examples are provided to demonstrate the convenience and validity of this design procedure.

4. $U$ tendons are more rational in terms of the loadcarrying mechanism and suitable for two types of anchorage zones. One-way tendons remain worth applying considering the advance in constructability, but they should not be used in thin anchorage zones, particularly when $\lambda$ is less than 0.5 .

\section{Acknowledgements}

The authors thank Dr. Quansheng Yan for his support and suggestions for this work.

\section{Funding}

This work was supported by the $<$ National Natural Science Foundation of China \#1> under Grant [11672108 and 11202080]; < Qingdao Postdoctoral Sustentation Fund $\# 2>$ under Grant [2017201]; and < the Science and technology project of Guangdong transportation department \#3> under Grant [science and technology-2012-02-024].

\section{Author contributions}

All authors contributed to the main idea of this paper. Shiping Huang and Nannan Cui carried out the analysis. Nannan Cui and Shiping Huang wrote the article.

\section{Disclosure statement}

The authors declare that they have no competing interest regarding the publication of this paper.

\section{References}

ACI Committee 318. (2008). Building code requirements for structural concrete (ACI318-08) and commentary (ACI 318R-08). American Concrete Institute, Farmington Hills (MI), USA.

Association of State Highway and Transportation Officials (AASHTO). (1999). Guide specifications for design and construction of segmental concrete bridges. Washington (DC), USA.
Association of State Highway and Transportation Officials (AASHTO). (2004). LRFD bridge specifications SI units ( $3^{\text {rd }}$ ed.). Washington (DC), USA.

Bendsoe, M. P., \& Sigmund, O. (2013). Topology optimization: Theory, methods, and applications. Berlin: Springer Science \& Business Media.

Canadian Standards Association (CSA). (1994). Design of concrete structure: Structures design. Rexdale (ON), Canada.

CEB-FIP MC 1990. (1993). Design code. London: Thomas Telford Services Ltd.

Cui, N. N., Jia, B. Y., Yu, X. L., Mai, Z. H., Yang, Z., \& Yan, Q. S. (2016). Full-scale model test of pylon anchorage zone with one-way prestressing tendons in cable-stayed bridge. Journal of Hunan University (Natural Sciences), 43(5), 61-69 (in Chinese).

Cui, N. N., Jia, B. Y., Yu, X. L., Yang, Z., \& Yan, Q. S. (2015). Investigation into prestress loss of short straight tendons in pylon anchorage zone of cable-stayed bridge. Journal of South China University of Technology (Natural Science), 43(12), 7784 (in Chinese).

Eurocode 2. (2004). Design of concrete structures: Part 1-1: General rules and rules for buildings. London: Thomas Telford Services Ltd.

He, Z.-Q., \& Liu, Z. (2010). Optimal three-dimensional strutand-tie models for anchorage diaphragms in externally prestressed bridges. Engineering Structures, 32, 2057-2064. https://doi.org/10.1016/j.engstruct.2010.03.006

Ji, L. (2005). The collection of Runyang Yangtze River bridge construction. Beijing: China Communication Press.

Jia, H., Misra, A., Poorsolhjouy, P., \& Liu, C. (2017). Optimal structural topology of materials with micro-scale tensioncompression asymmetry simulated using granular micromechanics. Materials \& Design, 115, 422-432. https://doi.org/10.1016/j.matdes.2016.11.059

Liang, Q. Q., \& Steven, G. P. (2002). A performance-based optimization method for topology design of continuum structures with mean compliance constraints. Computer Methods in Applied Mechanics and Engineering, 191(13), 1471-1489. https://doi.org/10.1016/S0045-7825(01)00333-4

Liang, Q. Q., Brian, U., \& Steven, G. P. (2002) Performance-based optimization for strut-tie modeling of structural concrete. Journal of Structural Engineering, 128(6), 815-823. https://doi.org/10.1061/(ASCE)0733-9445(2002)128:6(815)

Liang, Q. Q., Xie, Y. M., \& Steven, G. P. (2000). Topology optimization of strut-and-tie models in reinforced concrete structures using an evolutionary procedure. ACI Structural Journal, 97(2), 322-330. https://doi.org/10.14359/863

Meng, J., Wu, H. W., \& Zheng, H. H. (2016). Prestress design for concrete pylon anchorage zone based on the strut-and-tie models. Structural Engineers, 32(1), 5-9 (in Chinese).

Schlaich, J., Kurt, S., \& Mattias, J. (1987). Toward a consistent design of structural concrete. PCI Journal. 32(3), 74-150. https://doi.org/10.15554/pcij.05011987.74.150

Su, Q. T., Yang, G. T., Qin, F., \& Wu, C. (2012). Investigation on the horizontal mechanical behavior of steel-concrete composite cable-pylon anchorage. Journal of Constructional Steel Research, 24(6), 36-40. https://doi.org/10.1016/j.jcsr.2012.01.004

Tang, H. Y. (2006). Study on key problems of cable-stayed bridge PC pylon (PhD thesis). Southeast University, Nanjing, China.

Tao, H. (2007). Study on key problems of concrete cable-stayed bridges base on three-dimensional analysis ( $\mathrm{PhD}$ thesis). Tongji University, Shanghai, China. 
Tao, H., \& Xiao, R. H. (2008). Strut and tie model of prestress design for pylon anchor of concrete cable stayed bridges. Structural Engineers, 24(6), 36-40 (in Chinese).

Tao, Q. Y. (2012). Study on key issues in the PC pylon of long-span cable-stayed bridge ( $\mathrm{PhD}$ thesis). Southwest Jiaotong University, Chengdu, China.

Tao, Q. Y., Ye, H. W., Hu, J. C., \& Xu, X. (2017a). Horizontal STM and application of pre-stressed pylon anchorage zones of cable-stayed bridge. Sichuan Building Science, 43(3), 10-15 (in Chinese).

Tao, Q. Y., Ye, H. W., Hu, J. C., \& Xu, X. (2017b). Study on vertical strut-and-tie model in side wall of concrete cable bent tower anchorage zone of large-span cable-stayed bridge. Railway Engineering, 17(7), 16-20 (in Chinese).

Tjhin, T., \& Kuchma, D. (2007) Integrated analysis and design tool for the strut-and-tie method. Engineering Structures, 29(11), 3042-3052. https://doi.org/10.1016/j.engstruct.2007.01.032

Wu, B., Lu, H., \& Chen, B. (2017). Study on finite element model updating in highway bridge static loading test using spatially distributed optical fiber sensors. Sensors, 17(7), 1657. https://doi.org/10.3390/s17071657
Xia, Z., Li, A, Li, J., \& Duan, M. (2017). FE model updating on an in-service self-anchored suspension bridge with extra-width using hybrid method. Applied Sciences, 7(2), 191. https://doi.org/10.3390/app7020191

Xie, Y. M., \& Steven, G. P. (1993). A simple evolutionary procedure for structural optimization. Computers \& Structures, 49(5), 885-896. https://doi.org/10.1016/0045-7949(93)90035-C

Xiong, Z. H., Liu Y. J., Tian, W. M., \& Song, S. L. (2013). Application of topologically optimized strut-and-tie model to pylon anchorage zone. Bridge Construction, 43(4), 74-79 (in Chinese).

Ye, H. W., Li, C. J., Xu, X., Xiao, L., \& Qiang, S. Z. (2014). Fullscale model test of pre-stressed cable-pylon anchorage for single-oblique-pylon cable-stayed bridges. Journal of Southwest Jiaotong University, 49(1), 52-58 (in Chinese).

Zhai, H. N. (2008). Experimental study of horizontal behavior of the anchorage zone on pylon of the third Yellow River Bridge in Jinan (MSc thesis). Tongji University, Shanghai, China.

Zhu, J. W., Wang, J. B., \& Feng, Y. C. (2017). Topologically optimized strut-and-tie model and structural analysis of prestress for anchorage zone in pylon. Bridge Construction, 47(5), 5964 (in Chinese). 